\title{
Severe Obstructive Sleep Apnoea Leading to Raised Intracranial Pressure Hydrocephalus in a Patient with Aqueduct Stenosis
}

\author{
Hilary McLoughlin ${ }^{1}$, Gearoid Coughlan ${ }^{1}$, Iftikhar Nadeem ${ }^{2}$, Emma Burke $^{1}$ \\ ${ }^{1}$ Portiuncula University Hospital, Ballinasloe, Ireland \\ ${ }^{2}$ Lister Hospital, Stevenage, United Kingdom
}

Received: 20/12/2020

Accepted: 22/12/2020

Published: 14/01/2021

\begin{abstract}
How to cite this article: McLoughlin H, Coughlan G, Nadeem I, Burke E. Severe obstructive sleep apnoea leading to raised intracranial pressure hydrocephalus in a patient with aqueduct stenosis. EJCRIM 2021;8: doi:10.12890/2020_002229.
\end{abstract}

Conflicts of Interests: The Authors declare that there are no competing interests.

This article is licensed under a Commons Attribution Non-Commercial 4.0 License

\section{ABSTRACT}

We present the case of a patient with severe obstructive sleep apnoea (OSA) and hypoventilation syndrome who had hydrocephalus and acquired aqueduct stenosis. A link between these conditions in our patient is postulated. We discuss the mechanisms through which this might have occurred and the potential problems which might arise in applying non-invasive ventilation to a patient with hydrocephalus.

\section{LEARNING POINTS}

- Patients with severe obstructive sleep apnoea (OSA) and hypoventilation require AVAPS-AE ventilation to deal with obstructive and central events which may occur.

- Arterial blood gas analysis and MRI of the brain are indicated in the assessment of patients with severe OSA.

- Hydrocephalus may develop in patients with severe OSA if there is a structural brain abnormality but may resolve with OSA treatment.

\section{KEYWORDS}

Severe obstructive sleep apnoea, raised intracranial pressure hydrocephalus, aqueduct stenosis

\section{CASE DESCRIPTION}

A 52-year-old woman presented for respiratory evaluation because of a fragmented sleep pattern and daytime somnolence for 6 months. She had gained $31 \mathrm{~kg}$ in weight over 3 years after bereavement. She had been noted to fall asleep at work and to snore. She reported frequent nightmares. She was a non-smoker and non-drinker and weighed $127 \mathrm{~kg}$. There were no other abnormal clinical findings. She was booked for an urgent sleep study and was admitted for the study 2 weeks later. She was now lethargic in her responses. Her blood pressure was 186/87 $\mathrm{mmHg}$, heart rate was 93 beats/min, oxygen saturations were $89 \%$ on room air and respiratory rate was 20/min. Her Early Warning Score was 1.

\section{Investigations}

The limited sleep study showed severe OSA with obesity hypoventilation (Figs. 1 and 2). The Apnoea Hypopnea Index was 119.8/hour, the Respiratory Disturbance Index was 119.3/hour, and the Central Apnoea Index was 20.3/hour. The maximum apnoea duration was $123 \mathrm{sec}$, with an average apnoea duration of $21 \mathrm{sec}$. Heart rate ranged from 40 to 182 beats per minute. Significant periodic limb movements were noted ( 27 per hour). The lowest oxygen saturation recorded was $43 \%$ with an average saturation of $70 \%$. 

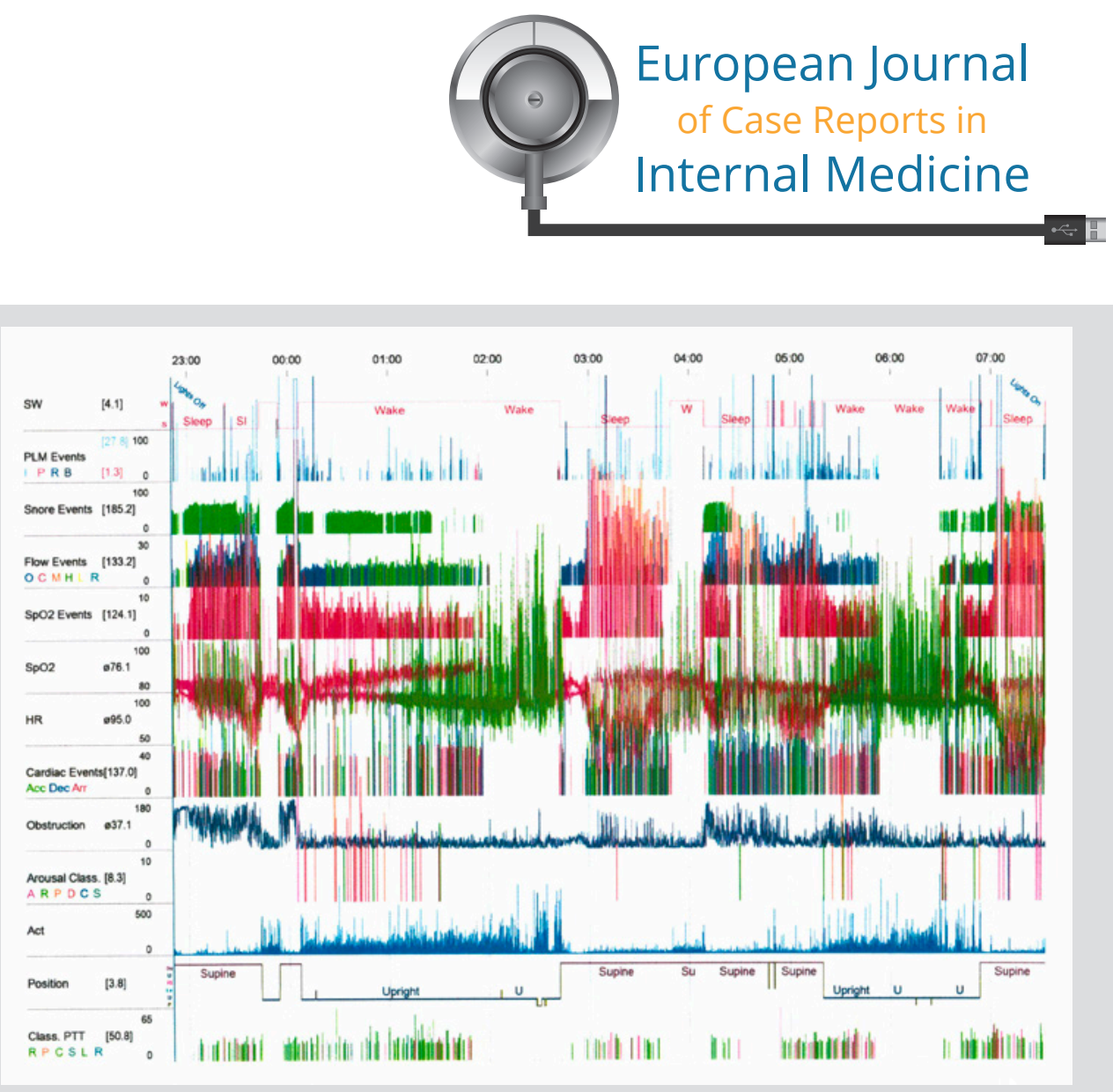

Figure 1. Limited sleep study
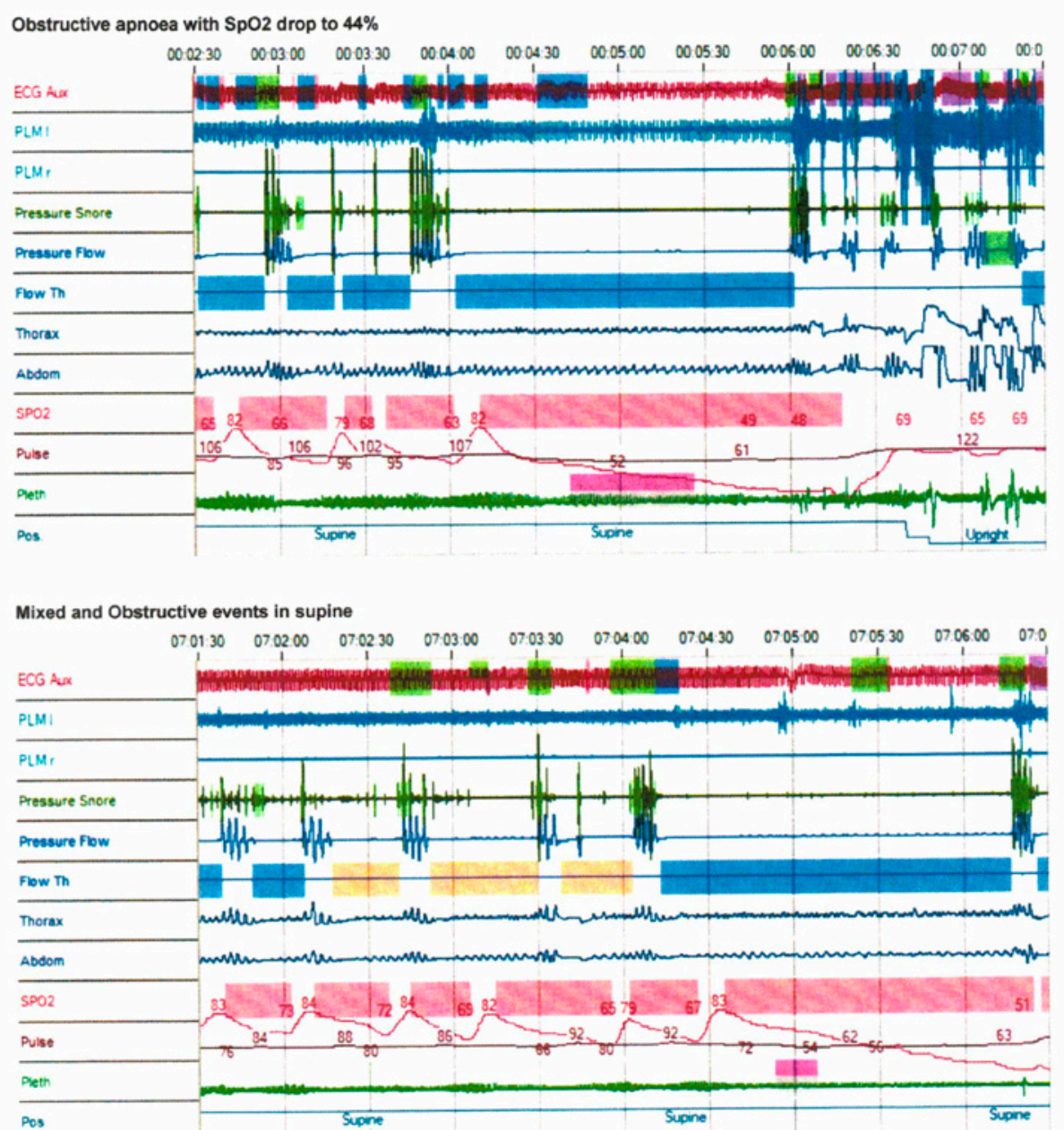
Arterial blood gas (ABG) analysis revealed a pH of 7.28, $\mathrm{pCO}_{2}$ of $10.1 \mathrm{kPa}, \mathrm{pO}_{2}$ of $8.2 \mathrm{kPa}$, and a standard bicarbonate level of $29 \mathrm{mmol} / \mathrm{l}$. A chest $x$-ray revealed consolidation in the right lower lobe. An echocardiogram showed good left ventricular function (71\%) with left ventricular hypertrophy. The right heart chambers had normal dimensions. Blood results showed a normal white cell count, and normal liver and renal function. CRP was $11 \mathrm{mg} / \mathrm{l}$.

Despite improvement, the patient remained vague and lethargic. A CT of the brain was performed and revealed hydrocephalus, with dilatation of the third ventricles and a normal fourth ventricle, suggesting stenosis of the aqueduct. This was confirmed on MRI of the brain (Figs. 3-5). Chronic microvascular ischaemic changes were present. No mass lesions or infarcts were identified and vascular flow voids were normal. Transependymal cerebrospinal fluid (CSF) flow was suggested by subependymal T2 hyperintensity. Interstitial oedema was evident. A neurosurgical opinion was sought and a ventriculoperitoneal shunt was deemed unnecessary at the time.

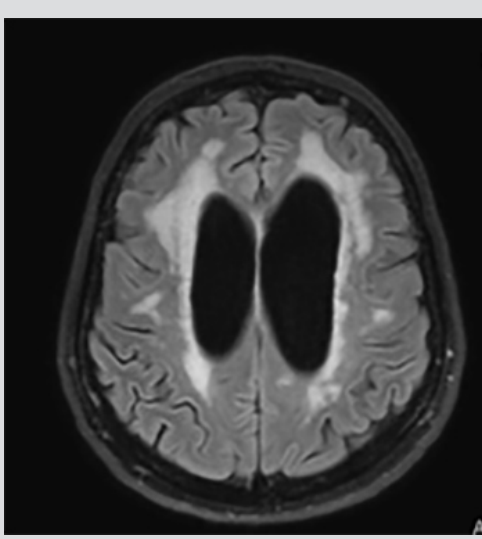

Figure 3. MRI of the brain shows microvascular ischaemia and hydrocephalus

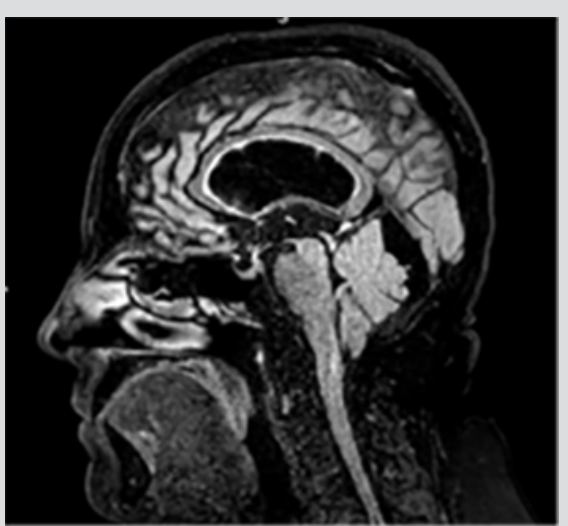

Figure 4. MRI of the brain: sagittal images showing dilated third ventricles with a normal fourth ventricle

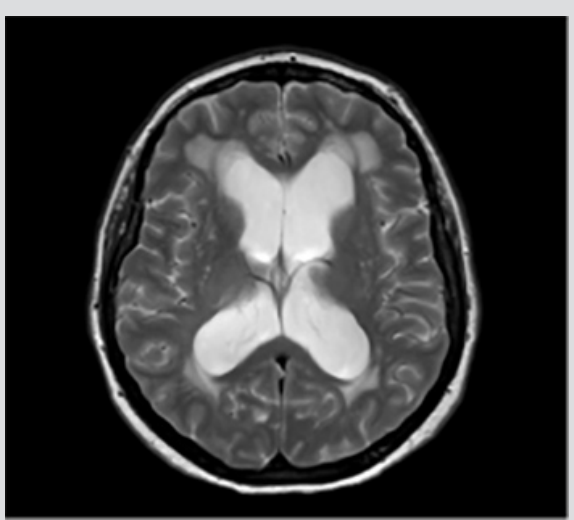

Figure 5. MRI of the brain showing interstitial oedema

\section{Clinical course}

The patient was commenced on AVAPS-AE ventilation (Average Volume Assured Pressure Support with Autotitration: EPAP 10-13, pressure support 10-15, breath rate 12, tidal volume $400 \mathrm{ml}$, timed inspiration $1.0 \mathrm{sec}$, humidity 3 ). The acidosis corrected within 4 hours and $\mathrm{pCO}_{2}$ dropped to $8 \mathrm{kPa}$. The patient continued to improve over the next few days. She was given coamoxiclav for her respiratory tract infection and amlodipine for her hypertension. She was discharged after 3 days and returned to work abroad. Discharge arterial blood gas analysis showed $\mathrm{pH} 7.42, \mathrm{pCO}_{2} 6.7$ and $\mathrm{pO}_{2} 8.6$ on room air.

One month later the patient was electively admitted for further investigation of her hydrocephalus. A lumbar puncture with manometry was performed in the seated position due to the patient's obesity. CSF pressure was elevated at $36 \mathrm{mmHg}$ (normal 10-15 mmHg); even allowing for the seated position this was deemed to be elevated pressure. The patient was doing very well on AVAPS-AE. Downloaded data from her device demonstrated greatly improved parameters (Table 1).

\begin{tabular}{|l|l|}
\hline Apnoea/Hypopnoea Index & $6.5 /$ hour \\
\hline Central Apnoea Index & $0 /$ hour \\
\hline Average tidal volume & $466 \mathrm{ml}$ \\
\hline Leak & $231 / \mathrm{min}$ \\
\hline Respiratory rate & $15 / \mathrm{min}$ \\
\hline Patient triggered breaths & $75 \%$ \\
\hline
\end{tabular}

Table 1. AVAP-AE data downloaded 1 month after initial presentation 
In the interim, a previous MRI scan for the patient, carried out 5 years earlier, had been identified at another institution. This demonstrated deep white matter ischaemia. There was no evidence of hydrocephalus or aquaduct stenosis at that time. In light of the previously normal MRI of the brain, the patient was referred back to the neurosurgeons for re-consideration of ventriculoperitoneal shunt insertion.

Four months after the initial acute presentation, 3-day intraventricular manometry was performed. Intracranial pressure (ICP) was found to be normal and ventriculoperitoneal shunt insertion was not indicated.

Our patient is now well and has been switched to Auto-CPAP treatment. She is complying well with therapy and has lost $42 \mathrm{lb}$ in weight.

\section{DISCUSSION}

Our patient presented with severe decompensated OSA. Because she appeared confused despite her pCO2 normalising on AVAPS-AE, CT of the brain was performed and revealed new hydrocephalus.

The association between OSA and idiopathic normal pressure hydrocephalus (iNPH) has been described in the literature, but there is very little information regarding the effects of sleep disordered breathing on raised ICP. Patients are described who have had both OSA and raised pressure hydrocephalus in addition to a structural abnormality such as syringomyelia. Our patient was found to have aquaduct stenosis. Evidence for the effect of OSA on ICP has been documented. Sugita et al. ${ }^{[1]}$ inserted monitoring catheters into the subarachnoid lumbar space in three adult male patients with known obstructive sleep apnoea and found that intermittent rises in CSF pressure were always preceded by obstructive airway events. They found a correlation between the duration of the apnoeas and the level of increase in CSF pressure.

There are several mechanisms by which obstructive sleep apnoea could give rise to raised ICP: hypoxia and hypercapnia can lead to cerebral vasodilatation which results in increased cerebral blood flow and an increase in cerebral vascular volume. Jennum et al. ${ }^{[2]}$ described increases in arterial blood pressure, and found that these increases correlated with ICP in patients with OSA. The ICP increased during nonREM sleep stages, but was highest during REM sleep, perhaps due to longer apnoeas detected during REM sleep. The authors concluded that haemodynamic changes occur during apnoeic episodes leading to impairment of cerebral circulation and cerebral ischaemia in the post-apnoeic phase. Kristensen et al. ${ }^{\left[{ }^{3]}\right.}$ suggested that repetitive ICP variations predisposed to increased ICP and the development of hydrocephalus. In their study, they found no correlation between the respiratory disturbance index (RDI) and the CSF pressure. Furthermore, they did not reduce the RDI by inserting a shunt and reducing the CSF pressure, suggesting that either the conditions were merely coexisting or that permanent damage had already been done by the hydrocephalus prior to the shunt placement. Other studies cite improvements in central apnoeas after ventricular shunt placement ${ }^{[4]}$.

Our patient had 119 obstructive apnoeas/hypopnoeas per hour. The Central Apnoea Index was 20/hour. She did not have discernible aquaduct stenosis on her CT of the brain 5 years earlier, although she had microvascular ischaemia which may itself lead to increased venous resistance leading to decreased CSF absorption and ventricular enlargement. We postulate that our patient developed aquaduct stenosis due to the microvascular ischaemia. The response to this ischaemic injury may have been local gliosis, a non-specific reactive change involving hypertrophy or proliferation of glial cells in the periventricular and aquaduct region. Arachnoid fibrosis is another possible mechanism. Studies in patients with normal pressure hydrocephalus who had frontal lobe biopsies suggested a process of meningeal fibrosis and obliteration of the subarachnoid space ${ }^{[5]}$. A similar pathology may exist in patients with raised ICP. Our patient had raised ICP as measured by manometry at lumbar puncture. This had normalised by the time intracranial manometry was performed after 4 months of AVAPS-AE treatment.

The potential for worsening of our patient's hydrocephalus with non-invasive ventilation was a possibility but did not occur. Decreasing the $\mathrm{pCO}_{2}$ to normal is an effective means to reduce ICP. Hyperventilating a patient acts to cause constriction of the cerebral vessels and lowers arteriolar blood flow ${ }^{[6]}$. This could have led to increased cerebral ischaemia. The recommendation therefore is to use such techniques for short periods only in raised ICP situations. The standard use of Spontaneous Timed mode with the use of a back-up breath rate only for periods of apnoeas was a safe and effective treatment for our patient. 


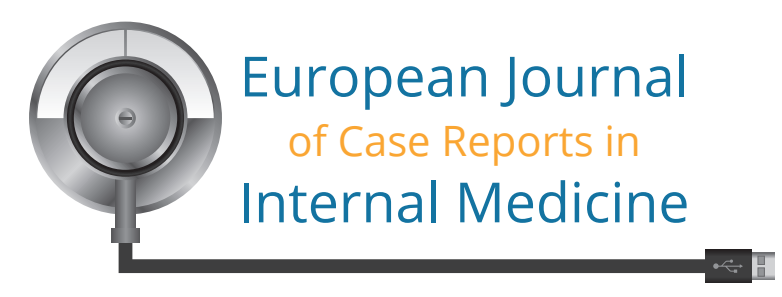

\section{REFERENCES}

1. Sugita Y, lijima S, Teshima Y, Shimizu T, Nishimura N, Tsutsumi T, et al. Marked episodic elevation of cerebrospinal fluid pressure during nocturnal sleep in patients with sleep apnoea hypersomnia syndrome. Electroencephalogr Clin Neurophysiol 1985;60:214-219.

2. Jennum P, Børgesen SE. Intracranial pressure and obstructive sleep apnea. Chest 1989;95:279-283.

3. Kristensen B, Malm J, Rabben T. Effects of transient and persistent cerebrospinal fluid drainage on sleep disordered breathing in patients with idiopathic adult hydrocephalus syndrome. J Neurol Neurosurg Psychiatry 1998;65:497-501.

4. Oliviera MF, Nacif SR, Castellano O, Sousa UO, Rotta JM, Pinto FCG. Improvement of central sleep apnoeas following ventricular shunt for normal pressure hydrocephalus. J Neuropsychiatry Clin Neurosci 2015;27(3):e206-208.

5. Bech RA, Waldemar G, Gjerris F, Klinken L, Juhler M. Shunting effects in patients with idiopathic normal pressure hydrocephalus with cerebral and leptomeningeal biopsy findings. Acta Neurochir (Wien)1999;141(6):633-639.

6. Sankhyan N, Vykunta Raju KN, Sharma S, Gulati S. Management of raised intracranial pressure. Indian J Paediatr 2010;77:1409-1416. 